\title{
The Gas6 gene rs8191974 and Ap3s2 gene rs2028299 are associated with type 2 diabetes in the northern Chinese Han population
}

\author{
Elena V. Kazakova\#, Tianwei Zghuang\#, Tingting Li, Qingxiao Fang, Jun Han and Hong Qiao ${ }^{凶}$ \\ 1The Fifth Endocrine Department, the Second Affiliated Hospital, Harbin Medical University, Harbin, Heilongjiang, China
}

Previous studies in other countries have shown that single nucleotide polymorphisms (SNPs) in the growth arrest-specific gene 6 (Gas6; rs8191974) and adapter-related protein complex 3 subunit sigma-2 (Ap3s2; rs2028299) were associated with an increasedrisk for type 2 diabetes mellitus (T2DM). However, the association of these loci with T2DM has not been examined in Chinese populations. We performed a replication study to investigate the association of these susceptibility loci with T2DM in the Chinese population. We genotyped 1968 Chinese participants (996 with T2DM and 972controls) for rs8191974 in Gas6 and rs2028299 near Ap3s2, and examined their association with T2DM using a logistic regression analysis. We also analyzed the correlation of genotypes and clinical phenotypes. The distribution of the $T$ allele of SNP rs8191974 in the Gas6 gene was significantly different between T2DM cases and controls when compared with the $C$ allele $(P<0.05$, OR: $0.80,95 \%$ $\mathrm{Cl}$ : 0.69-0.94). The occurrence of the CT genotype and the dominant model was also significantly less frequent in the T2DM cases vs. controls when compared with the CC genotype (CT vs. CC: $P<0.05$, OR: 0.75, 95\% Cl:0.62-0.90; TT+CT vs. CC: $P<0.05$, OR:0.75, 95\% $\mathrm{Cl}: 0.63-0.90)$. In SNP rs2028299, the allele C showed no statistically significant differencein distribution between the control and T2DM groups when compared with allele A. However, in male populations, the dominant model was statistically more frequent when compared with genotype AA $(C C+C A$ vs. AA: $P<0.05$, OR:1.29, 95\% Cl:1.02-1.64), and in obesity-stratified analysis, we also observed a significant difference in the distribution of the dominant model between the T2DM cases and controls in subjects with $B M I \geq 24 \mathrm{~kg} /$ $\mathrm{m}^{2}$ and $\mathrm{BMI}<28 \mathrm{~kg} / \mathrm{m}^{2}(\mathrm{CC}+\mathrm{CA}$ vs. AA: $P<0.05$, OR: 6.33 , 95\% Cl:4.17-9.61). In conclusion, our study shows that SNPsrs8191974 and rs2028299 are significantly associated with T2DM in the Chinese population.

Key words: Type 2 diabetes mellitus; Gas6 gene; Ap3s2 gene; single nucleotide polymorphisms; epidermal growth factor (EGF)-like

Received: 09 October, 2016; revised: 26 October, 2016; accepted: 05 Januray, 2017; available on-line: 11 April, 2017

e-mail: qiaoh0823@sina.com

\#These authors contributed equally to this work.

Abbreviations: BMI, body mass index; HDL, high-density lipoprotein cholesterol; LDL, low-density lipoprotein cholesterol; HOMA- $\beta$ homeostasis model assessment of beta-cell function; HOMA-IR, homeostasis model assessment of insulin resistance

\section{INTRODUCTION}

Diabetes mellitus affects more than 300 million individuals worldwide, with increasing prevalence particularly in the developing countries (Whiting et al., 2011). In fact, the prevalence of type 2 diabetes mellitus (T2DM) in China is among the highest in the world. The combination of insulin resistance in peripheral tissues and impaired insulin secretion from pancreatic $\beta$-cells is believed to contribute to the development and progression of T2DM. Both, the genetic and environmental factors confer susceptibility to T2DM. In recent years, studies of gene polymorphisms have helped identify a number of T2DM-susceptibility genes.

The growth arrest-specific gene 6 (Gas6) is located on human chromosome 13q34. Plasma Gas6 is a vitamin K-dependent protein very similar to plasma anticoagulant protein $\mathrm{S}$ and is comprised of the Gla domain $(\gamma$-carboxylated glutamicacid-rich region) and four EGF-likedomains (Bellido-Martin et al., 2008). Gas6 protein interacts with receptor tyrosine kinases of the Tyro-3, Axl, Mer(TAM) family (Hafizi et al., 2006). The Gas6/TAM system has a number of diverse functions, including the regulation of cell survival and proliferation, cell adhesion and migration, and others (Godowski et al., 1995; Nagata et al., 1996; Bellosta et al., 1997; Collett et al., 2003;). In recent years, several studies have explored the relationship between Gas6 polymorphisms and T2DM. Chien-Hsing Lee in Taiwan found that the Gas6 gene single nucleotide polymorphism (SNP) rs8191974 was associated with T2DM in the local population (Lee et al., 2012).

The adapter-related protein complex 3 subunit sigma-2 gene (Ap3s2) is located on human chromosome $15 \mathrm{q} 26$, and was first foundin muscle tissue of rats. Ap3s2 protein is composed of 193 amino acids and its physiological function involves protein transport. Two studies have reported that Ap3s2 gene SNP rs2028299 was associated with T2DM. A genome-wide association study (GWAS) in people of South Asian ancestry identified rs2028299 as asusceptibility locus for T2DM (Kooner et al., 2011). A replication study investigating the association of SNP rs2028299 with T2DM in the Japanese population (Fukuda et al., 2012). Found that SNP rs2028299 had a significant effect on the susceptibility of Japanese people toT2DM (Fukuda et al., 2012).

To our knowledge, the role of the Gas6 and Ap3s2 genes inT2DM in the Han population has not been previously assessed. Given the apparent association between SNP rs8191974 and SNP rs2028299 with T2DM, we further investigated whether SNP rs8191974 and SNP rs2028299 are related to T2DM in Chinese people. 
Table 1. Clinical characteristics in patients and controls.

\begin{tabular}{llll}
\hline & NGT & T2DM & $P$ value \\
\hline Sex (M/F) & $568 / 404$ & $612 / 384$ & 0.1731 \\
\hline Age (years) & $42.87 \pm 11.67$ & $46.11 \pm 12.55$ & $<0.0001$ \\
\hline Height & $1.69 \pm 0.08$ & $1.68 \pm 0.08$ & 0.0801 \\
\hline Weight & $66.55 \pm 12.37$ & $73.13 \pm 13.45$ & $<0.0001$ \\
\hline BMI & $23.31 \pm 3.34$ & $25.78 \pm 3.58$ & $<0.0001$ \\
\hline Waistline & $81.25 \pm 10.84$ & $93.49 \pm 10.44$ & $<0.0001$ \\
\hline Hipline & $95.77 \pm 7.2$ & $99.48 \pm 7.44$ & $<0.0001$ \\
\hline Waist-to-hip ratio & $0.85 \pm 0.07$ & $0.94 \pm 0.06$ & $<0.0001$ \\
\hline Systolic & $121.24 \pm 15.08$ & $130.17 \pm 17.5$ & $<0.0001$ \\
\hline Diastolic & $79.21 \pm 9.64$ & $84.64 \pm 11.17$ & $<0.0001$ \\
\hline Fasting glucose & $4.82 \pm 0.33$ & $10.03 \pm 3.41$ & $<0.0001$ \\
\hline TC & $4.88 \pm 1.05$ & $5 \pm 1.29$ & 0.0289 \\
\hline TG & $1.42 \pm 0.96$ & $2.38 \pm 2.25$ & $<0.0001$ \\
\hline HDL & $1.48 \pm 0.37$ & $1.21 \pm 0.32$ & $<0.0001$ \\
\hline LDL & $1.92 \pm 0.87$ & $2.91 \pm 1.26$ & $<0.0001$ \\
\hline HOMA-IR & $1.51 \pm 1.15$ & $4.81 \pm 3.91$ & $<0.0001$ \\
\hline HOMA- $\beta$ & $104.78 \pm 74.62$ & $38.42 \pm 37.51$ & $<0.0001$ \\
\hline
\end{tabular}

\section{MATERIALS AND METHODS}

Study population. All subjects were recruited from outpatient clinics of the Second Affiliated Hospital, Harbin Medical University, Heilongjiang, China. Basic parameters were collected from each subject, including name, age, gender, height, weight, waist circumference, hip circumference, blood pressure, plasma lipids, fasting

Table 2. Correlation analysis of Gas6 rs8191974 and Ap3s2 rs2028299 alleles with T2DM.

\begin{tabular}{|c|c|c|c|c|c|}
\hline Gene & Allele & controls(972) & T2DM(996) & $\mathrm{Pa}$ & ORa $(95 \% \mathrm{Cl})$ \\
\hline \multirow{2}{*}{ Ap3s2 } & A & $1573(80.92 \%)$ & $1566(78.61 \%)$ & \multirow{2}{*}{0.0725} & \multirow{2}{*}{$1.1534(0.9870-1.3478)$} \\
\hline & C & $371(19.08 \%)$ & $426(21.39 \%)$ & & \\
\hline \multirow{2}{*}{ Gas6 } & C & $1465(75.36 \%)$ & $1577(79.17 \%)$ & \multirow{2}{*}{0.0044} & \multirow{2}{*}{$0.8049(0.6931-0.9364)$} \\
\hline & $\mathrm{T}$ & $479(24.64 \%)$ & $415(20.83 \%)$ & & \\
\hline
\end{tabular}

Abbreviations: $\mathrm{Cl}$, confidence interval: $\mathrm{OR}$, odds ratio. aAdjusted for age, gender and BMI.

Table 3. Correlation analysis of Gas6 rs8191974 and Ap3s2 rs2028299 genotypes with T2DM.

\begin{tabular}{|c|c|c|c|c|c|}
\hline Gene & Genotype & Controls & T2DM & $\mathrm{Pa}$ & ORa $(95 \% C l)$ \\
\hline \multirow{5}{*}{ Ap3s2 } & AA & 637 (65.53\%) & $613(61.55 \%)$ & \multirow{3}{*}{0.1809} & 1 \\
\hline & $C A$ & $299(30.76 \%)$ & $340(34.14 \%)$ & & $1.18(0.98-1.43)$ \\
\hline & CC & $36(3.7 \%)$ & $43(4.32 \%)$ & & $1.24(0.79-1.96)$ \\
\hline & AA & 637 (65.53\%) & 613 (61.55\%) & \multirow{2}{*}{0.0661} & \multirow{2}{*}{$1.19(0.99-1.43)$} \\
\hline & $\mathrm{CC}+\mathrm{CA}$ & 335 (34.47\%) & 383 (38.45\%) & & \\
\hline \multirow{5}{*}{ Gas6 } & $\mathrm{CC}$ & $550(56.58 \%)$ & 632 (63.45\%) & \multirow{3}{*}{0.0078} & 1 \\
\hline & CT & 365 (37.55\%) & $313(31.43 \%)$ & & $0.75(0.62-0.90)$ \\
\hline & $\pi$ & 57 (5.86\%) & $51(5.12 \%)$ & & $0.78(0.52-1.16)$ \\
\hline & $\mathrm{CC}$ & $550(56.58 \%)$ & $632(63.45 \%)$ & \multirow{2}{*}{0.0019} & \multirow{2}{*}{$0.75(0.63-0.90)$} \\
\hline & $T+C T$ & $422(43.42 \%)$ & 364 (36.55\%) & & \\
\hline
\end{tabular}

aAdjusted for age, gender and BMI. blood glucose, homeostasis model assessment of insulin resistance (HOMA-IR) and HOMA of beta-cell function (HOMA- $\beta$ ). We used the case control study methods to analyze the association between Gas6 gene rs8191974, Ap3s2 gene rs2028299 and T2DM. The case group included 1000 patients with T2DM, and the control group included 1000 healthy human subjects. Inclusion criteria for the control subjects were as follows: 1) Hemoglobin A1c level $<6.0 \%$; 2) fasting plasma glucose level $<5.1$ $\mathrm{mmol} / \mathrm{L}$; 3) no history of diabetes; 4) no family history of T2DM; 5) not taking drugs that affect lipid and carbohydrate exchange; and 6) no systemic diseases. Exclusion criteria for this study were as follows: 1) renal and hepatic failure; 2) cardiovascular disease; 3) acute diabetic complications; 4) malignant tumors, severe injury, infections, or other endocrine diseases; or 5) other types of diabetes.

DNA extraction and genotype analysis. DNA was obtained from blood samples using the TIANGEN whole blood DNA extraction kit and following the manufacturer's instructions. The quality of isolated genomic DNA waschecked using agarose gel electrophoresis and quantitation wasdetermined using spectrophotometry. The Gas6 gene SNP rs8191974 and Ap3s2 gene SNP rs2028299 genotyping was performed using commercial SNPscan Genotyping assays from Applied Biosystems

istical methods. Descriptive results of continuous variables areexpressed as means \pm standard error of the mean. Before statistical analysis was performed, nordistribution and homogeneity ofvariables was evaluated by using the Levene's test, and if necessary, a base ogarithmic transformation was applied. The $\mathrm{x}^{2}$-test was used to determine the genotype distributions for HardyWeinberg equilibrium and to compare the observedallele and genotype frequencies in patients with those in control subjects. Statistical significance was considered to be $P<0.05$. Logistic regression analyses were performed with SPSS (Chicago, Illinois, USA; version 13.0) and the odds ratio (OR) and 95\% confidence interval (CI) were calculated for each variant genotype compared to the homozygous wildtype genotype.

\section{RESULTS}

\section{Subject Characteristics}

There were four cases in the T2DM group and 28 cases in the control group without genotypes, so the final study included 996 T2DM patientsand 972 control subjects.

Characteristics of the subjects are shown in Table 1. A slightly higher proportion of older subjects were observed among T2DM patients compared to controls, which may be due to a participation bias. In the T2DM group, BMI, waistline, hipline, waist-hip ratio, systolic and diastolic blood pressure, fasting glucose, total 
Table 4. Gender stratification analysis of Ap3s2 rs2028299 alleles/genotypes with T2DM.

\begin{tabular}{|c|c|c|c|c|c|}
\hline & Allele/Genotype & NGT & T2DM & $\mathrm{Pa}$ & $\mathrm{OR}^{\mathrm{a}}(95 \% \mathrm{Cl})$ \\
\hline \multicolumn{6}{|l|}{ Male } \\
\hline & A & $373(67.70 \%)$ & $365(62.50 \%)$ & & 1 \\
\hline & $C$ & $178(32.30 \%)$ & $219(37.50 \%)$ & 0.022 & $1.26(1.03-1.54)$ \\
\hline & AA & $373(65.67 \%)$ & 365 (59.64\%) & \multirow{3}{*}{0.0680} & 1 \\
\hline & CA & $178(31.34 \%)$ & $219(35.78 \%)$ & & $1.26(0.98-1.61)$ \\
\hline & $\mathrm{CC}$ & 17 (2.99\%) & $28(4.58 \%)$ & & $1.68(0.91-3.13)$ \\
\hline & AA & $373(65.67 \%)$ & $365(59.64 \%)$ & \multirow{2}{*}{0.0325} & \multirow{2}{*}{$1.29(1.02-1.64)$} \\
\hline & $\mathrm{CC}+\mathrm{CA}$ & $195(34.33 \%)$ & $247(40.36 \%)$ & & \\
\hline \multicolumn{6}{|l|}{ Female } \\
\hline & A & $264(68.57 \%)$ & $248(67.21 \%)$ & & 1 \\
\hline & $\mathrm{C}$ & $121(31.43 \%)$ & $121(32.79 \%)$ & 0.993 & $1.00(0.78-1.28)$ \\
\hline & AA & $264(65.35 \%)$ & $248(64.58 \%)$ & \multirow{3}{*}{0.7932} & 1 \\
\hline & CA & $121(29.95 \%)$ & $121(31.51 \%)$ & & $1.06(0.78-1.45)$ \\
\hline & $\mathrm{CC}$ & $19(4.7 \%)$ & $15(3.91 \%)$ & & $0.84(0.42-1.69)$ \\
\hline & AA & $264(65.35 \%)$ & $248(64.58 \%)$ & 0.8224 & $1.03(0.77-1.39)$ \\
\hline & $\mathrm{CC}+\mathrm{CA}$ & 140 (34.65\%) & $136(35.42 \%)$ & & \\
\hline
\end{tabular}

adjusted for age, gender and BMI. Data are presented as means \pm S.D.

cholesterol, triglycerides, low density lipoprotein cholesterol, HOMA IR and HOMA- $\beta$ were significantly higher than in the control group.

\section{Correlation analysis of SNP rs8191974 and rs20228299with T2DM}

As displayed in Table 2, rs8191974 showed an allelic difference between cases and controls in the Chinese population, with an OR of 0.80 (95\% CI:0.69-0.94, $P=0.004)$; however, SNP rs2028299 showed no significant difference between the $\mathrm{A}$ and $\mathrm{C}$ alleles in the two groups.

We further analyzed the effect of the genotypes of the two SNPs under a dominant genetic model by logistic tests (Table 3). The CT genotype and the dominant model displayed significant differences between cases and controls when compared with the CC genotype (CT vs. CC: $P<0.05$, OR:0.75, 95\% CI:0.62-0.90; TT+CT vs. CC: $P<0.05$, OR:0.75, 95\% CI:0.63-0.90).

In the male populations, the dominant model was significantly different when compared with the AA genotype (CC +CA vs. AA; P<0.05, OR:1.29, 95\% CI:1.021.64; Table 4). In the female subjects, there were no differences in any genotype between the two groups ( $\mathrm{Ta}$ ble 4).

Table 5. BMI stratification analysis of Ap3s2 rs2028299 genotypes with T2DM.

\begin{tabular}{llllll}
\hline Gene & Genotype & Control & T2DM & Pa & ORa $^{a}(95 \% \mathrm{Cl})$ \\
\hline $24 \leq \mathrm{BMI}<28$ & & & & \\
\hline Ap3s2 & AA & $292(90.40 \%)$ & $256(64.42 \%)$ & 1 \\
\hline & CA & $18(5.58 \%)$ & $150(31.84 \%)$ & 0.0001 & $9.50(5.67-15.94)$ \\
\hline & CC & $13(4.02 \%)$ & $22(3.75 \%)$ & & $1.93(0.95-3.91)$ \\
\hline & AA & $292(90.40 \%)$ & $256(64.42 \%)$ & \\
\hline CC+CA & $31(9.60 \%)$ & $172(35.58 \%)$ & 0.0001 & $6.33(4.17-9.61)$ \\
\hline
\end{tabular}

aAdjusted for age, gender and BMI.
Associations between SNPs and T2DM Characteristics

Subjects were further divided into groups with different genotypes and the main clinical and biological characteristics are summarized in $\mathrm{Ta}$ ble 6. We found that weight, waist, hip and fasting glucose were significantly differentfor every rs8191974 genotype by analyzing the association between the genotypes and clinical phenotypes $(P<0.05)$. The CA heterozygote of rs2028299 was significantly associated with increased weight $(P<0.05)$.

\section{DISCUSSION}

To date, more than 120 genetic loci have been suggested to be associated with T2DM, or with glucose and insulin levels in the European and multi-ethnic populations (Sladek et al., 2007; Zeggini et al., 2008; Dupuis et al., 2010; Imamura et al., 2011; Lyssenko et al., 2015). Of these, several loci have been shown to be associated with T2DM in different ethnic groups, whereas the remaining loci have not shown any significant effects in the ethnic populations other than those in the original reports. Although the power of these studies may be insufficient in some cases, genetic heterogeneity among different ethnicities may exist for some particular loci. In this study, we examined the association of SNP rs8191974 and rs2028299 with susceptibility to T2DM in a Chinese population and showed that they were significantly associated.

Previous studies indicated that the Gas6/TAM system was involved in the pathogenic mechanism for renal and cardiovascular complications associated with diabetes (Nagai et al., 2003; Cavet et al., 2008). Recent studies in animal models have shown that Gas6/TAM signaling plays an important role in pathophysiological mechanisms underlying obesity-related inflammation and insulin resistance (IR) (Augustine et al., 1999). Hsieh et al., had suggested that the Gas6 gene variants were associated with IR, although their effects on subsequent progression to T2DM were minimal in this study (Hsieh et al., 2015). It is also important to mention that the Gas6 polymorphism has been associated with stroke (Muñoz et al., 2004; Muñoz et al., 2007). The Hsieh study conducted in Taiwan had shown that the Gas6 gene rs8191974 mutations reduced the risk of T2DM (Lee et al., 2012). Likewise, our study found that the SNP rs8191974 $\mathrm{T}$ allelic gene is a protective factor in T2DM, consistent with the Taiwanese study (Lee et al., 2012). Northern and southern Chinese have obviously different living environments and lifestyles. However, 


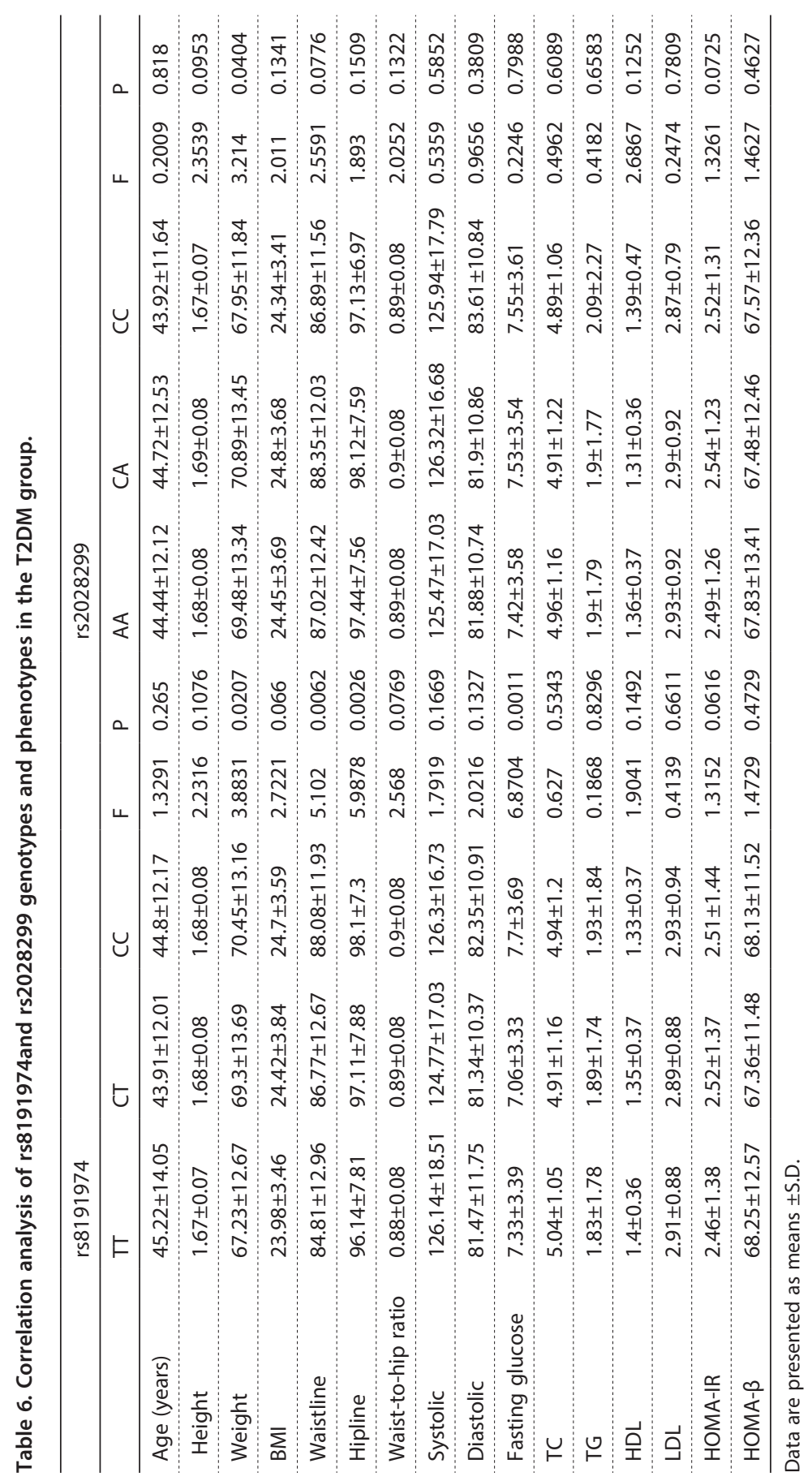

that SNP rs8191974 is associated with an increased risk of T2DM via these indicators. In recent years, increasing attention has been paid to the role of fattyacid toxicity in the pathogenesis of T2DM. We hypothesize that rs8191974 is likely to affect the risk of T2DM factors involving obesity and lipid metabolism in the pathogenesis of T2DM. This theory will require subsequent experimental verification.

The Ap3s2 protein is widely distributed in the islet and fat cells. A South Asian GWAS had shown that the Ap3s2 gene SNPrs2028299 had relatively strong links to T2DM (Kooner et al., 2011). In addition, the association of rs2028299 and T2DM was examined in a Japanese population in which it was shown that the genetic risk score was significantly associated with T2DM (Fukuda et al., 2012). Our study found that SNP rs2028299 allele $\mathrm{C}$ and dominant model $\mathrm{CC}+\mathrm{CA}$ vs. AA were risk factors for T2DM in males, but we observed no association between SNP rs2028299 and T2DM in females. It may be that subject variation among male and female participants or differing levels of sex hormones caused false negative results.

In a subsequent analysis to determine the association of SNP rs2028299 with weight, we found that subjects with the CA genotype had greater weight among all T2DM patients. It has been previously reported that SNP rs2028299 was associated with increased patient BMI levels (Fukuda et al., 2012), and studies have confirmed that excess weight or BMI can cause insulin resistance. Combining the results of our study and related literature reports (Kooner et al., 2011; Fukuda et al., 2012; van de Bunt et al., 2013), we suggest that SNP rs2028299 may participate in the occurrence and development of T2DM in one of the following ways: 1) Disturbing the intracellular localization of the insulin receptor substrate to affect insulin function; 2) Altering the expression of microRNAs in islet cells to affect the secretion of insulin;

the fact that both, our study and Lee et al. found that SNP rs8191974 was associated with T2DM, suggests that the contribution of genetic factors is greater than environmental factors in ChineseT2DM.

The molecular mechanisms by which the Gas6 gene participates in T2DM have not yet been elucidated. Lee $e t$ al. speculated that the Gas 6 gene polymorphisms participated in the occurrence and development of T2DM by altering the function of the islet cells (Lee et al., 2012). Among the T2DM group, we found that subjects with the rs8191974 CC genotype had higher glucose, weight, waistline and hipline values. It is well known that the three indicators of weight, waistline and hipline are commonly used measures of obesity, so it may be the case
3) Since SNP rs2028299 is widely expressed in fat cells, its mutations may increase the BMI of T2DM patients, which can lower insulin sensitivity and indirectly cause insulin resistance; 4) SNP rs2028299 may affect nearby loci that are correlated with T2DM and thus indirectly influence the occurrence and development of T2DM.

\section{CONCLUSION}

We have observed a significant association of Gas6 rs8191974 and Ap3s2 rs2028299 with type 2 diabetes in a Chinese population. Our results suggest that both SNPs are common T2DM susceptibility loci in differ- 
ent ethnic groups. However, further functional studies will be required to elucidate the biological mechanisms underlying each locus which confer susceptibility to the disease.

\section{Ethical considerations}

Ethical issues, including informed consent, plagiarism, misconduct, data fabrication and/or falsification, and double publication and/or submission, have been fully observed by the authors.

\section{Competing Interests}

The authors have declared that no competing interests exist.

\section{Acknowledgements}

We gratefully acknowledge the numerous sample donors for making this work possible.

\section{Funding}

This work was funded by the National Natural Science Foundation of China (81473053) and the Natural Science Foundation of Heilongjiang Province (SQ2013CB051164).

The funders had no role in study design, data collection and analysis, decision to publish, or preparation of the manuscript.

\section{REFERENCES}

Whiting DR, Guariguata L, Weil C, Shaw J (2011) IDF diabetes atlas: global estimates of the prevalence of diabetes for 2011 and 2030 . Diabetes Res Clin Pract 94: 311-321. doi: http://dx.doi.org/10.1016/j. diabres.2011.10.029

Bellido-Martin L, de Frutos PG (2008) Vitamin K-dependent actions of Gas6. Vitam Horm 78: 185-209. http://dx.doi.org/10.1016/ S0083-6729(07)00009-X

Hafizi S, Dahlback B (2006) Gas6 protein S. Vitamin K-dependent ligands for the Axl receptor tyrosine kinase subfamily. FEBS J 273: 5231-5244. doi: http://dx.doi.org/10.1111/j.17424658.2006.05529.x

Bellosta P, Zhang Q, Goff SP, Basilico C (1997) Signaling through the ARK tyrosine kinase receptor protects from apoptosis in the absence of growth stimulation. Oncogene 15: 2387-2397. http://dx.doi. org/10.1038/sj.onc.1201419

Nagata K, Ohashi K, Nakano T, Arita H, Zong C, Hanafusa $\mathrm{H}$ et al. (1996) Identification of the product of growth arrest-specific gene 6 as a common ligand for Axl, Sky, and Mer receptor tyrosine kinases. J BiolChem 271: 30022-30027. http://dx.doi.org/10.1074/ jbc.271.47.30022

Collett G, Wood A, Alexander MY, Varnum BC, Boot-Handford RP, Ohanian V et al. (2003) Receptor tyrosine kinase Axlmodulates the osteogenic differentiation of pericytes. Circ Res 92: 1123-1129. http://dx.doi.org/10.1161/01.RES.0000074881.56564.46
Godowski PJ, Mark MR, Chen J, Sadick MD, Raab H, Hammonds RG (1995) Reevaluation of the roles of protein S and Gas6 as ligands for the receptor tyrosine kinase Rse/Tyro 3. Cell 82: 355-358. http://dx.doi.org/10.1016/0092-8674(95)90424-7

Lee CH, Chu NF, Shieh YS, Hung YJ (2012) The growtharrest-specific6 (Gas6) gene polymorphism c.834+7G>A is associated with type 2 diabetes. Diabetes Res Clin Pract 95: 201-206. http://dx.doi. org/10.1016/j.diabres.2011.09.013

Kooner JS, Saleheen D, Sim X, Sehmi J, Zhang W et al. (2011) Genome-wide association study in individuals of South Asian ancestry identifies six new type 2diabetes susceptibility loci. Nat Genet 43: 984-989. http://dx.doi.org/10.1038/ng.921

Fukuda H, Imamura M, Tanaka Y, Iwata M, Hirose H et al. (2012) A single nucleotide polymorphism within DUSP9 is associated with susceptibility to type 2 diabetes in a Japanese population. PLoS One 7: e46263. http://dx.doi.org/10.1371/journal.pone.0046263

Lyssenko V, Groop L, Prasad RB (2015) Genetics of type 2 diabetes: it matters from which parent we inherit the risk. Rev Diabet Stud 12: 233-242. http://dx.doi.org/10.1900/RDS.2015.12.233

Imamura M, Maeda S (2011) Genetics of type 2 diabetes: the GWAS and future perspectives. Endocr J 58: 723-739

Sladek R, Rocheleau G, Rung J, Dina C, Shen L et al. (2007) A genome-wide association study identifies novel risk loci for type 2 diabetes. Nature 445: 881-885. http://dx.doi.org/10.1038/nature05616

Zeggini E, Weedon MN, Lindgren CM, Frayling TM, Elliott KS, et al. (2007) Replication of genome-wide association signal in U.K. samples reveals risk loci for type 2 diabetes. Science 316: 1336-1341. http://dx.doi.org/10.1126/science.1142364

Dupuis J, Langenberg C, Prokopenko I, Saxena R, Soranzo N, et al. (2010) New genetic loci implicated in fasting glucose homeostasis and their impact on type 2 diabetes risk. Nat Genet 42: 105-116. http://dx.doi.org/10.1038/ng.520

Nagai K, Arai H, Yanagita M, Matsubara T, Kanamori H, Nakano T, et al. (2003) Growth arrest-specific gene 6 is involved in glomerular hypertrophy in the early stage of diabetic nephropathy. I Biol Chem 278: 18229-18234. http://dx.doi.org/10.1074/jbc.M213266200

Cavet ME, Smolock EM, Ozturk OH, World C, Pang J, Konishi A, et al. (2008) Gas6-axl receptor signaling is regulated by glucose in vascular smooth muscle cells. Arterioscler Thromb V asc Biol 28: 886-891. http://dx.doi.org/10.1161/ATVBAHA.108.162693

Augustine KA, Rossi RM, Van G, Housman J, Stark K, Danilenko $\mathrm{D}$, et al. (1999) Non-insulin-dependent diabetes mellitus occurs in mice ectopically expressing the human Axl tyrosine kinase receptor. J Cell Physiol 181: 433-447. http://dx.doi.org/10.1002/(SICI)10974652(199912)181:3<433::AID-JCP7>3.0.CO;2-Y

Hsieh CH, Chung RH, Lee WJ, Lin MW, Chuang LM, Quertermous T, Assimes T, Hung YJ, Yu YW (2015) Effect of common genetic variants of growth arrest-specific 6 gene on insulin resistance, obesity and type 2 diabetes in an Asian population. PLoS One 10: http:// dx.doi.org/10.1371/journal.pone.0135681

Sumoy L, Ramírez-Lorca R, Villar J, de Frutos PG, Sala N (2004) Human vitamin K-dependent GAS6: gene structure, allelic variation, and association with stroke. Hum Mutation 23: 506-512. http://dx. doi.org/10.1002/humu.20025

Muñoz X1, Obach V, Hurtado B, de Frutos PG, Chamorro A, Sala $\mathrm{N}$ (2007) Association of specific haplotypes of GAS6 gene with stroke. Thromb Haemost 98: 406-412. https://doi.org/10.1160/ TH06-12-0681

Van de Bunt M, Gaulton KJ, Parts L, Moran I, Johnson PR, et al. (2013) The miRNA profile of human pancreatic islets and beta-cells and relationship to type 2 diabetes pathogenesis. PLoS One 8: e55272. https://doi.org/10.1371/journal.pone.0055272 